"Ethical principles of medical research involving human subjects" (2000), the requirements of GCP, the applicable national legislation.

Results: Among patients with RA frequency of the genotypes was as follows: TT $-37.2 \%$, TC $-42.6 \%$, CC $-20.3 \%$. Age, seropositivity and the duration of the disease were not differing in patients with RA, carriers of the different genotypes of eNOS. Though, CC genotype was associated with high disease activity according to DAS28-ESR $>5.2$ (OR=9.60; 95\% Cl 2.18-42.2), $\mathrm{HAQ}>2$ $(\mathrm{OR}=2.38 ; 95 \% \mathrm{Cl}: 0.94-6.02)$ and extraarticular manifestations (OR $=3.26 ; 95 \%$ Cl 1.40-7.56).

After 12 weeks treatment we estimated, that among patients with TT genotype there were 58.3; 16.7; and 8.3\% responders ACR20; ACR50; ACR70, and among patients with $C C$ genotype $-20.0 ; 10.0 ; 0.0 \%(p<0.05)$. TC heterozygotes patients had lower (by $22-25 \%, \mathrm{p}<0.05$ ) clinical response to the treatment by DAS28 and $\mathrm{HAQ}$ than the homozygotes TT.

Conclusions: eNOS T-786C gene promoter polymorphism influence on the efficacy of the treatment, and CC genotype can be considered as a possible predictor of a low response to the treatment in patients with rheumatoid arthritis. References:

[1] Breedveld F.C., Weisman M.H., Kavanaugh A.F. et al. (2006) The PREMIER study. Arthr. Reum., 54: 26-37.

[2] Gonzalez-Gay M.A., Llorca J., Palomino-Morales R. et al. (2009) Influence of nitric oxide synthase gene polymorphisms on the risk of cardiovascular events in rheumatoid arthritis. Clin. Exp. Rheumatol., 27 (1): 116-119.

Disclosure of Interest: None declared

DOI: 10.1136/annrheumdis-2017-eular.3962

\section{SAT0697 PREVALENCE OF HEPATITIS B AND C INFECTION AND REACTIVATION IN PATIENTS RECEIVING BIOLOGIC IV THERAPIES}

K. Arévalo Ruales ${ }^{1}$, B. Soler Bas ${ }^{2}$, J. Ivorra Cortes ${ }^{1}$, E. Grau Garcia ${ }^{1}$, E. Vicens Bernabeu $^{1}$, E. Labrador Sánchez ${ }^{1}$, J.J. Fragio Gil ${ }^{1}$, R. González Mazarío ${ }^{1}$, C. Alcañiz Escandell ${ }^{1}$, I. Cánovas Olmos ${ }^{1}$, I. Chalmeta Verdejo ${ }^{1}$, C.M. Feced Olmos $^{1}$, L. Gonzalez Puig ${ }^{1}$, I. Martínez Cordellat ${ }^{1}$, C. Nájera Herranz ${ }^{1}$, R. Negueroles Albuixech ${ }^{1}$, J.E. Oller Rodriguez ${ }^{1}$, F.M. Ortiz-Sanjuan ${ }^{1}$, J.A. Román Ivorra ${ }^{1,2} .{ }^{1}$ Rheumatology Department, HUP la Fe; ${ }^{2}$ Medical School, UCV, Valencia, Spain

Background: With the use of biological therapy, cases of reactivation of hepatitis $B$ (HBV) and C (HCV) have been described, consequently its use has to be carefully evaluated. In some cases these therapies have to be administered together with antiviral treatment. Despite the fact that before the beginning of the biological therapy the screening of HBV and HCV virus is done, during the course of treatment serologies are no longer used to detect serovonversions.

Objectives: To analyze the prevalence of HBV and HCV in patients with rheumatic disease at the beginning of biological therapies. To identify the cases of hepatitis reactivation.

Methods: Retrospective observational analysis of the biological treatments administered to patients with rheumatic Disease of the rheumatology department of La Fe hospital, during the period 2000-2015 who had HBV and/or HCV serology at the beginning of treatment. Demographic data and diagnosis of the patient, months of treatment and the results of the serologies performed at the beginning and in the follow-up of the treatment, and the cases of reactivation of hepatitis have been collected.

Results: A total of 388 patients were selected of which $62.4 \%$ were female; the mean age at diagnosis of was $38.96 \pm 14.36$ years. $49.5 \%$ of the patients were diagnosed with rheumatoid arthritis (RA), $25.3 \%$ of ankylosing spondylitis (AE), $18.6 \%$ of psoriatic arthritis (APSO) and $6.7 \%$ with other diagnoses. The mean treatment time with patients' biological therapy is $200 \pm 118$ months (3-464 months), and the mean time between the two serologies is $172 \pm 102$ months (18-460 months). An incidence of $10 \%$ of cases with HBV infection (39 patients) is observed. The serological pattern was 8 cases with Ac-core (+) HBV/Ac-surface $(-) /$ Ag-surface (-) HBV and 31 HBV/Ac- surface (-). The incidence of HCV at the start of treatment was $1.1 \%$ (4 patients). A case of reactivation $(12.5 \%$ ) was detected among the 8 patients with Ac-core (+)/Ac-surface (-)/Ag-surface (-) HBV. The patient had infliximab and methotrexate, and reactivation was observed after 12 years of treatment. No reactivation of HCV has been detected.

Conclusions: In our series of patients the incidence of HBV and HCV has been $10 \%$ and $1.1 \%$, respectively. One of the 8 patients with Ac-core (+)/Ac-surface $(-) /$ Ag-surface (-) HBV, had reactivation of the virus.

Disclosure of Interest: None declared

DOI: 10.1136/annrheumdis-2017-eular.4827

\section{SAT0698 DISEASE ACTIVITY DURING AND AFTER PREGNANCY IN WOMEN WITH AXIAL SPONDYLOARTHRITIS}

K. Ursin ${ }^{1,2}$, S. Lydersen ${ }^{3}$, J. Skomsvoll ${ }^{1}$, M. Wallenius ${ }^{1,2}{ }^{1}$ National Advisory Unit on Pregnancy and Rheumatic Diseases, St. Olavs Hospital - Trondheim University Hospital; ${ }^{2}$ Department of Neuromedicine and Movement Science; ${ }^{3}$ Regional Centre for Child and Youth Mental Health, NTNU, Norwegian University of Science and Technology, Trondheim, Norway

Background: Studies on disease activity of ankylosing spondylitis in pregnancy have shown diverging results. A large retrospective study from 1998 without validated disease activity scores found no particular pattern of disease course during pregnancy (1). Later two small studies demonstrated a tendency towards lower disease activity in the beginning of pregnancy and deterioration in late pregnancy $(2,3)$. None of these studies included women with non-radiographic axial spondyloarthritis. The only large study was conducted before the widespread use of biological DMARDs.

Objectives: The aim of this project was to prospectively study disease activity in women with axial spondyloarthritis before, during and after pregnancy with BASDAI as disease activity measure.

Methods: RevNatus is a Norwegian nationwide register designed for the followup of pregnant women with rheumatic diseases. RevNatus included 181 full term pregnancies in 168 women with axial spondyloarthritis between 2006 and 2016. The women had seven visits at a rheumatology unit; before pregnancy, in each trimester, and six weeks, six months and twelve months postpartum. BASDAl-values from each visit were analyzed in a linear mixed model.

Results: Even though we found a statistically significant relationship between disease activity and time point in the follow-up period, our study demonstrated that women with axial spondyloarthritis had stable, low disease activity during and after pregnancy. Disease activity in second trimester was significantly higher than six weeks after delivery, but the change in estimated mean BASDAI was small (BASDAI 3.97 vs. BASDAI $3.46, p=0.005$ ). The figure below shows changes in disease activity throughout the study period.

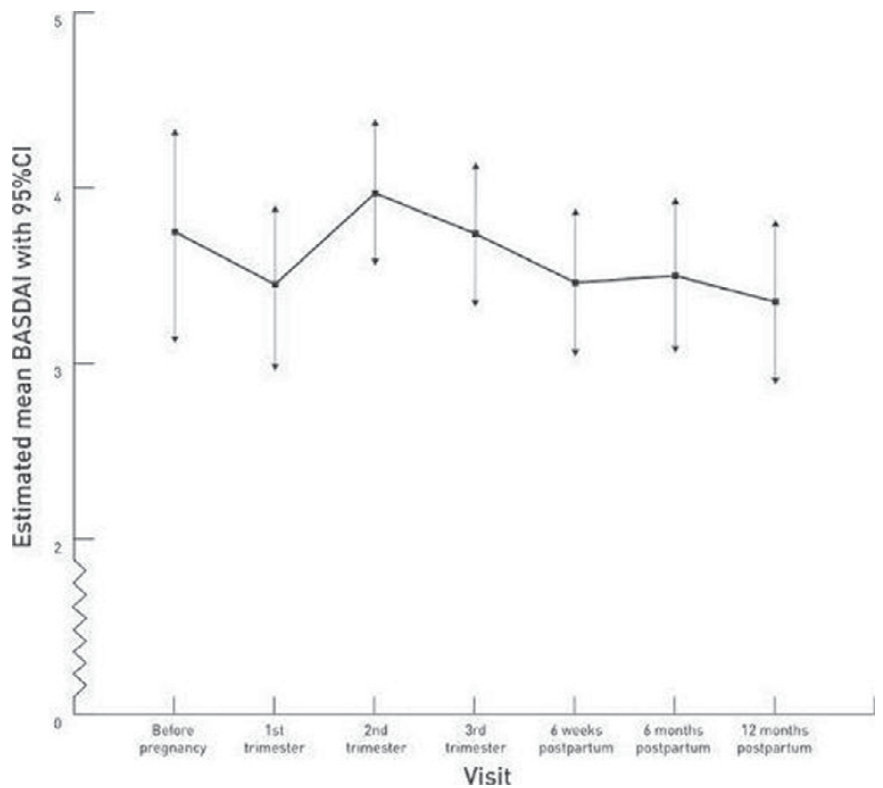

Conclusions: Studying women with axial spondyloarthritis, we found that disease activity was highest in second trimester, but altogether stable in the period from planning pregnancy to one year after delivery.

References:

[1] Ostensen M, Ostensen H. Ankylosing spondylitis - The female aspect. J Rheumatol. 1998;25(1):120-4.

[2] Ostensen M, Fuhrer L, Mathieu R, Seitz M, Villiger PM. A prospective study of pregnant patients with rheumatoid arthritis and ankylosing spondylitis using validated clinical instruments. Ann Rheum Dis. 2004;63(10):1212-7.

[3] Lui NL, Haroon N, Carty A, Shen H, Cook RJ, Shanmugarajah S, et al. Effect of pregnancy on ankylosing spondylitis: A case-control study. J Rheumatol. 2011;38(11):2442-4.

Disclosure of Interest: None declared

DOI: 10.1136/annrheumdis-2017-eular.1604

\section{SAT0699 RAPID ASSESSMENT PREDICTS DISEASE ACTIVITY IMPROVEMENT IN NEWLY DIAGNOSED RHEUMATOID ARTHRITIS (RA)}

M. Yates ${ }^{1}$, J. Galloway ${ }^{1}$, N. Snowden ${ }^{2}$, S. Norton ${ }^{1}$, J.M. Ledingham ${ }^{3}$ E.M. Dennison ${ }^{4}$, A. Rivett ${ }^{5}$, A.J. Macgregor ${ }^{6} .{ }^{1}$ Academic Rheumatology, King's College London, London; ${ }^{2}$ Rheumatology Dept, Pennine MSK Partnership, Oldham; ${ }^{3}$ Rheumatology Dept, Portsmouth Hospitals NHS Trust, Portsmouth; ${ }^{4} M R C$, Southampton University, Southampton; ${ }^{5} B S R$, The British Society for Rheumatology, London; ${ }^{6}$ Rheumatology Dept, Norfolk and Norwich University Hospital, Norwich, United Kingdom

Background: Early intervention in RA is associated with improved outcomes in randomised trials. UK guidelines stipulate that those with suspected RA are assessed by a rheumatologist within 3 weeks of referral. However, there are limited real world data confirming the value of early assessment. Previous work suggests social deprivation predicts severe disease at presentation and a worse 